\begin{tabular}{|c|c|}
\hline Title & Chemokines in bronchiolar epithelium in the development of chronic obstructive pulmonary disease. \\
\hline Author(s) & Fuke, Satoshi; Betsuy aku, Tomoko; Nasuhara, Y asuy uki; Morikawa, Toshiaki; Katoh, Hiroy uki; Nishimura, Masaharu \\
\hline Citation & $\begin{array}{l}\text { A merican Journal of Respiratory Cell and Molecular Biology, 31(4), 405-412 } \\
\text { https://doi.org/10.1165/rcmb.2004-01310C }\end{array}$ \\
\hline Issue Date & 200410 \\
\hline Doc URL & http:/hdl .handle.net/2115/17090 \\
\hline Type & article \\
\hline File Information & A JRC\&MB31-4.pdf \\
\hline
\end{tabular}

Instructions for use 


\title{
Chemokines in Bronchiolar Epithelium in the Development of Chronic Obstructive Pulmonary Disease
}

\author{
Satoshi Fuke, Tomoko Betsuyaku, Yasuyuki Nasuhara, Toshiaki Morikawa, Hiroyuki Katoh, and Masaharu Nishimura \\ First Department of Medicine and Second Department of Surgery, Hokkaido University School of Medicine, Sapporo, Japan
}

The inflammatory chemokines interleukin-8, macrophage inflammatory protein- $1 \alpha$, and monocyte chemoattractant protein-1, are reportedly involved in the pathogenesis of chronic obstructive pulmonary disease (COPD). Although bronchiolar epithelial cells and macrophages are known to be the cellular sources, the relative contribution of each cell type remains to be elucidated. In the present study, we first quantified cytokine mRNA in human bronchiolar epithelial cells and macrophages obtained using laser-capture microdissection and explored the relationship with early-stage COPD. Only in bronchiolar epithelial cells were interleukin-8, macrophage inflammatory protein-1 $\alpha$, and monocyte chemoattractant protein-1 mRNA levels higher in smokers with airflow limitation and/or emphysema than those in never-smokers or smokers without either airflow limitation or emphysema. No difference was observed in macrophages. Complementary DNA (cDNA) array further revealed the overexpression of CC chemokine receptor 2 in bronchiolar epithelial cells from smokers with airflow limitation and/or emphysema. This study supports the role of bronchiolar epithelium as the source of increased inflammatory chemokine levels in the early development of COPD and also demonstrates the potential use of laser-capture microdissection, combined with reverse transcriptase-polymerase chain reaction and cDNA microarrays, to investigate functional profiles of individual structural and inflammatory cells in human lungs.

Although terminal bronchioles are known to be critical in a variety of smoking-related lung diseases (1) and are the major sites of airflow limitation in smokers $(2,3)$, quantitative analysis of the expression of inflammatory mediators by bronchiolar epithelial cells has been limited because of the difficulty in harvesting cells from living subjects. In contrast, larger airway epithelial cells have been well characterized in numerous studies $(4,5)$. Using a new ultrathin fiberscope, Takizawa and colleagues harvested a sufficient number of living epithelial cells from the peripheral airways of volunteers to produce single-cell suspensions for short-term cell culture. In smokers, intercellular adhesion molecule-1 and interleukin (IL)- 8 were upregulated in epithelial cells from the small airways, but not from the large airways, thus suggesting the site-dependent characteristics of airway epithelial cells in response to smoking (6). However, this novel approach suffers from the possibility of inducing cellular changes resulting from disrupting cell-cell and cell-matrix rela-

(Received in original form April 26, 2004 and in revised form June 19, 2004)

Address correspondence to: Tomoko Betsuyaku, M.D., Ph.D., First Department of Medicine, Hokkaido University School of Medicine, N-15, W-7, Kita-ku, Sapporo, Japan, 060-8638. E-mail: bytomoko@med.hokudai.ac.jp

Abbreviations: bronchoalveolar lavage, BAL; CC chemokine receptor 2, CCR2; cluster of differentiation 68, CD68; complementary DNA, cDNA; computed tomography, CT; chronic obstructive pulmonary disease, COPD; forced expiratory volume in one second, $\mathrm{FEV}_{1}$; forced vital capacity, FVC; glyceraldehyde3-phosphatase-dehydrogenase, GAPDH; horseradish peroxidase, HRP; interleukin, IL; laser-capture microdissection, LCM; monocyte chemoattractant protein, MCP; macrophage inflammatory protein, MIP; phosphate-buffered saline, PBS; reverse transcriptase-polymerase chain reaction, RT-PCR.

Am. J. Respir. Cell Mol. Biol. Vol. 31, pp. 405-412, 2004

Originally Published in Press as DOI: 10.1165/rcmb.2004-01310C on June 25, 2004

Internet address: www.atsjournals.org tionships, digesting cell surface proteins, and incubating cells in culture conditions. While in situ hybridization and immunohistochemistry are useful for analysis of a small number of mRNAs and protein gene products in situ, and has indeed characterized the expression of inflammatory chemokines in bronchiolar epithelial cells in chronic obstructive pulmonary disease (COPD) $(7,8)$, these techniques may not be practical for analysis of large numbers of mRNAs or gene products.

Microdissection techniques have, in recent years, become an accepted approach for harvesting specific cell types in tissues for downstream applications of DNA, RNA, and protein analysis without disrupting the in vivo status of the cells (9). Lasercapture microdissection (LCM) is now a widely used approach to microdissection (10). Betsuyaku and colleagues first reported that application of LCM coupled with quantitative reverse transcriptase-polymerase chain reaction (RT-PCR) permitted analysis of cell-specific gene expression in terminal bronchiolar epithelial cells in a bleomycin mouse model (11). The aim of this study was to use LCM to isolate bronchiolar epithelial cells and macrophages from surgically resected lung tissue to quantify cell typespecific gene expression of three inflammatory chemokines that are reportedly relevant to the pathogenesis of COPD: IL-8, macrophage inflammatory protein (MIP)- $1 \alpha$, and monocyte chemoattractant protein (MCP)-1. The tissues used in this study were derived from lifelong never-smokers, smokers without either airflow limitation or emphysema, and smokers with airflow limitation and/or emphysema who were considered to have early-stage COPD. We further subjected the RNA from LCM-retrieved bronchiolar epithelial cells to complementary DNA (cDNA) array analysis to explore the possibility that expression of multiple chemokine and chemokine receptor genes are affected during the early stages of COPD.

\section{Materials and Methods}

\section{Subjects}

Lung tissue specimens were obtained from 30 patients who underwent lung resection for small peripheral tumors. Steady-state measurements of vital capacity, forced expiratory volume in one second $\left(\mathrm{FEV}_{1}\right)$, and diffusing capacity were performed in all subjects (CHESTAC-55V; Chest Co., Tokyo, Japan) before surgery. Airflow limitation was defined as an $\mathrm{FEV}_{1}$ /forced vital capacity (FVC) of less than $70 \%$. Highresolution chest computed tomography (CT) scans were performed in all subjects and the presence of emphysematous changes was determined as previously described (12). Subjects were classified into three groups: 10 never-smokers ( 2 males and 8 females); 10 smokers without either airflow limitation or emphysema ( 8 males and 2 females); and 10 smokers with airflow limitation and/or emphysema (9 males and 1 female). None of the subjects had a history of asthma, nor did any subjects suffer from acute respiratory infections in the preceding month. Smoking history was documented in a questionnaire in which the duration of smoking and the amount of currently and previously smoked cigarettes (pack-years) were specifically addressed. Informed consent was obtained from each subject and the Ethics Committee of Hokkaido University School of Medicine approved the study protocols. None of the subjects was on regular medication for respiratory disease. 


\section{Tissue Preparation}

Six or more blocks of lung tissue $(1.0 \times 1.0 \times 0.5 \mathrm{~cm})$ were randomly removed from freshly excised, tumor-free peripheral lung as soon as possible after resection. Tissue specimens were inflated with diluted Tissue-Tek OCT (Sakura Finetek U.S.A., Torrance, CA) (50\% vol/vol) in RNase-free phosphate-buffered saline (PBS) containing 10\% sucrose using a $10-\mathrm{ml}$ syringe with a $22 \mathrm{G}$-needle. Each block was placed in the base of a cryomold (Sakura Finetek U.S.A.), carefully overlaid with additional Tissue-Tek OCT, and was immediately frozen with dry ice (usually $\sim 2 \mathrm{~min}$ ). The pieces of lung were kept flat in the bottom of the cryomold to maximize the area of tissue that was sectioned. To minimize RNA degradation, we typically produced frozen blocks of tissue within $5 \mathrm{~min}$ of lobe removal from the thoracic cavity. Each block was individually wrapped in aluminum foil and stored at $-80^{\circ} \mathrm{C}$ until sectioning.

\section{Sampling of Bronchiolar Epithelial Cells by LCM}

Tissues were sectioned at $7 \mu \mathrm{m}$ in a cryostat (Leica, Nussloch, Germany). Frozen sections were placed on plain glass slides (Matsunami, Osaka, Japan) and were then immediately fixed in $70 \%$ ethanol for 5 min before being rehydrated in RNase-free water for $30 \mathrm{~s}$. Tissue was then stained with $0.5 \%$ Nissl (cresyl violet acetate) (Sigma Chemical, St. Louis, MO)/0.1 M sodium acetate buffer for $15 \mathrm{~s}$, followed by dehydration in a graded series of $70 \%, 95 \%$, and $100 \%$ (twice) ethanol (30 s each) and cleaning in xylene for $9 \mathrm{~min}$ ( 3 times for $3 \mathrm{~min}$ each) before LCM. Slides were completely air-dried to prevent activation of endogenous RNase in the tissues. LCM of bronchiolar epithelial cells was performed using a PixCell II System (Arcturus Engineering, Mountain View, CA) with the following parameters: laser diameter, $15 \mu \mathrm{m}$; pulse duration, $1.5 \mathrm{~ms}$; amplitude, 25-50 mW. After samples were captured on transfer films (CapSure Transfer Film TF-100; Arcturus Engineering), nonspecific attached components were removed using adhesive tape (CapSure Pad; Arcturus Engineering). Bronchiolar epithelial cells were retrieved from the terminal bronchiole and proximally along airways of up to $\sim 500 \mu \mathrm{m}$ in diameter. At least 6 bronchioles were randomly selected and a total of 40,000 laser bursts were used to collect cells from each subject's specimen.

\section{Sampling of Macrophages by Immuno-LCM}

We made slight modifications to the reported protocol of immunoLCM (13). To identify macrophages in the lung, sections were stained with mouse monoclonal anti-human cluster of differentiation 68 (CD68) antibodies (Dako, Carpinteria, CA) as previously reported (14) using an EnVision ${ }^{+}$kit (Dako). Tissues were cut and fixed in $70 \%$ ethanol for $5 \mathrm{~min}$ and washed in RNase-free water for $30 \mathrm{~s}$ as above. Sections were then washed in PBS twice for $30 \mathrm{~s}$ each and incubated in antiCD68 antibody at a 1:40 dilution in PBS containing $400 \mathrm{U} / \mathrm{ml}$ RNase inhibitor (Applied Biosystems, Foster City, CA) for 5 min. After washing in PBS, sections were exposed to a horseradish peroxidase (HRP)labeled polymer conjugated with secondary mouse and rabbit antibodies from the kit for $5 \mathrm{~min}$. After washing in RNase-free water and PBS, sections were incubated with diaminobenzidine for $2 \mathrm{~min}$ and were washed in RNase-free water. Sections were then dehydrated as above and cleaned in xylene for $90 \mathrm{~s}$ ( 3 times for $30 \mathrm{~s}$ each) before LCM. Slides were completely air-dried until use to prevent RNA degradation. RNase inhibitor $(400 \mathrm{U} / \mathrm{ml})$ was added in all aqueous steps, including color development. Macrophages localized in the alveolar space and in the alveolar walls were harvested by LCM as described above using a laser beam diameter of $7.5 \mu \mathrm{m}$. A total of 30,000 laser bursts were used to collect cells from each subject.

\section{RNA Purification and Reverse Transcription}

Total RNA was extracted from LCM samples from bronchiolar epithelial cells and macrophages, as well as from the serial sections adjacent to the sections used for LCM, referred to as whole sections of lung tissue, using an RNeasy Mini kit (Qiagen, Hilden, Germany), and was eluted in $31 \mu \mathrm{l}$ of elution buffer included in the kit. RNA was reversetranscribed using random hexamers from the TaqMan Reverse Transcription Reagents and RT Reaction Mix (Applied Biosystems) in a total volume of $60 \mu \mathrm{l}$ at $25^{\circ} \mathrm{C}$ for $10 \mathrm{~min}$, at $42^{\circ} \mathrm{C}$ for $30 \mathrm{~min}$, and at $94^{\circ} \mathrm{C}$ for 5 min on the ABI PRISM 7,700 Sequence Detection System
(Applied Biosystems). The resulting first-strand cDNA was used as a template for RT-PCR.

\section{5'-Exonuclease-Based Fluorogenic PCR}

Quantitative PCR was performed using an ABI PRISM 7,700 Sequence Detector (Applied Biosystems) as described previously (11). Oligonucleotide PCR primer pairs and fluorogenic probes for IL-8 were designed based on published sequences using Primer Express software (Applied Biosystems) (15). Assays-on-Demand gene expression probes were used for MIP-1 $\alpha$ and MCP-1, and were derived from the boundary of exons 1 and 2 of the human MIP-1 $\alpha$ gene sequence (GenBank accession number: NM002983) and from the boundary of exons 1 and 2 of the human MCP-1 gene sequence (GenBank accession number: NM002982) (Applied Biosystems). Primers and a labeled probe for glyceraldehyde-3-phosphatase-dehydrogenase (GAPDH) cDNA as an endogenous control were purchased from Applied Biosystems (TaqMan human GAPDH control reagents). PCRs for the target gene and GAPDH were performed in separate tubes to avoid possible competition and/or interference (16). Briefly, a 2- $\mu$ l aliquot of the RT products (cDNA) from bronchiolar epithelial cells or from macrophages, or a $0.5-\mu l$ aliquot of those from whole lung sections, was placed into each tube and PCR was performed using TaqMan Universal PCR Master Mix (Applied Biosystems) in a total volume of $25-\mu 1$. PCR was performed for 40 cycles, consisting of a denaturation step at $95^{\circ} \mathrm{C}$ for $15 \mathrm{~s}$ and a combined annealing and extension step at $60^{\circ} \mathrm{C}$ for $1 \mathrm{~min}$. For linear regression analysis of unknown samples in each assay, a standard curve was generated using 8- or 10-fold serial dilutions of cDNA from human alveolar macrophages obtained by bronchoalveolar lavage (BAL) from a normal control subject as described previously (17). The relative amount of target mRNA in the samples was assessed by interpolation of their threshold cycles from a standard curve and was then normalized against GAPDH mRNA. PCR assay was independently performed three times to confirm reproducibility, and representative data are shown.

\section{cDNA Array Analysis}

The nonradioactive GEArray Q series cDNA expression array filters containing 77 chemokine and chemokine receptor genes (HS-005N; SuperArray Inc., Bethesda, MD) were used according to manufacturer's instructions (18). Because the number of cells obtained practically by LCM from one subject is not sufficient for cDNA array, even with the amplification step, and because we wanted to reduce the number of cDNA arrays used, bronchiolar epithelial cells were harvested by LCM bursting of 15,000 laser shots per person and were pooled from 10 subjects in each group. Total RNA from pooled cells was extracted as described above and was quantified using a NanoDrop ND-1000 Spectrophotometer (NanoDrop Technologies, Montchanin, DE). The ratio of absorbance at 260 and $280 \mathrm{~nm}$ was used to assess the purity of RNA. An aliquot of RNA (120 150 ng), of which the 260/280 ratio was $\sim 2.0$, was used to synthesize labeled cDNA probes with an AmpoLabeling-LPR kit (L-03; SuperArray Inc.), which was followed by hybridization to the filter. Relative amounts of mRNA transcripts on the filter were quantified using the Fluor-S Max MultiImager System combined with Quantity One (Bio-Rad, Hercules, CA). The relative amounts of a given gene transcript were estimated by comparing the signal intensity with the signal derived from GAPDH on each filter. A more than 2 -fold increase in signal intensity between groups was considered significant.

\section{Data Presentation and Statistical Analysis}

Group data are expressed as mean \pm SEM, or as median and range when appropriate. The statistical analysis was done by single factor analysis of variance, and then Fisher's protected least significant difference test was applied as a post hoc test for multiple comparisons in analysis of variance when appropriate in the StatView J 5.0 System (SAS Institute Inc., Cary, NC). Statistical significance was set at $P<0.05$.

\section{Results}

\section{Subjects}

Clinical characteristics of the subjects are summarized in Table 1. Subjects in each group are listed in order of decreasing $\mathrm{FEV}_{1}$ 
TABLE 1. Clinical characteristics of subjects

\begin{tabular}{|c|c|c|c|c|c|c|c|}
\hline & Age $(y r)$ & Sex & Pack-Years & Smoking Cessation & $\mathrm{FEV}_{1}(\%$ Pred $)$ & $\mathrm{FEV}_{1} / \mathrm{FVC}(\%)$ & Emphysema on HRCT \\
\hline \multirow[t]{10}{*}{ Never-smoker } & 79 & $\mathrm{~F}$ & 0 & & 154 & 79 & - \\
\hline & 74 & $\mathrm{~F}$ & 0 & & 128 & 74 & - \\
\hline & 87 & $\mathrm{~F}$ & 0 & & 116 & 72 & - \\
\hline & 63 & $\mathrm{~F}$ & 0 & & 113 & 93 & - \\
\hline & 67 & $\mathrm{~F}$ & 0 & & 112 & 80 & - \\
\hline & 56 & $\mathrm{~F}$ & 0 & & 106 & 71 & - \\
\hline & 65 & $\mathrm{~F}$ & 0 & & 103 & 77 & - \\
\hline & 72 & M & 0 & & 99 & 79 & - \\
\hline & 30 & $\mathrm{M}$ & 0 & & 82 & 82 & - \\
\hline & 58 & $\mathrm{~F}$ & 0 & & 71 & 75 & - \\
\hline \multicolumn{8}{|c|}{ Smoker without either airflow } \\
\hline \multirow[t]{10}{*}{ limitation or emphysema } & 78 & M & 168 & $7 \mathrm{~d}$ & 152 & 80 & - \\
\hline & 73 & M & 37 & $4 \mathrm{yr}$ & 128 & 82 & - \\
\hline & 67 & M & 10 & $27 \mathrm{yr}$ & 123 & 91 & - \\
\hline & 73 & M & 56 & $8 \mathrm{yr}$ & 123 & 80 & - \\
\hline & 39 & $\mathrm{~F}$ & 20 & $2 \mathrm{mo}$ & 122 & 90 & - \\
\hline & 47 & $\mathrm{~F}$ & 11 & $14 \mathrm{~d}$ & 103 & 82 & - \\
\hline & 31 & M & 17 & $1.5 \mathrm{mo}$ & 101 & 82 & - \\
\hline & 70 & $\mathrm{M}$ & 90 & $9 \mathrm{yr}$ & 94 & 76 & - \\
\hline & 68 & M & 41 & $9 \mathrm{yr}$ & 81 & 89 & - \\
\hline & 63 & $\mathrm{M}$ & 65 & $7 \mathrm{~d}$ & 71 & 75 & - \\
\hline \multirow[t]{10}{*}{$\begin{array}{l}\text { Smoker with airflow limit } \\
\text { and/or emphysema }\end{array}$} & 76 & M & 20 & $16 \mathrm{yr}$ & 126 & 60 & + \\
\hline & 77 & $\mathrm{M}$ & 100 & $3 \mathrm{yr}$ & 112 & 59 & + \\
\hline & 54 & $\mathrm{M}$ & 85 & $9 \mathrm{~d}$ & 101 & 79 & + \\
\hline & 53 & $\mathrm{M}$ & 30 & $2 \mathrm{yr}$ & 99 & 77 & + \\
\hline & 76 & $\mathrm{M}$ & 56 & $1.5 \mathrm{mo}$ & 97 & 62 & + \\
\hline & 77 & $\mathrm{M}$ & 46 & $12 \mathrm{yr}$ & 96 & 64 & + \\
\hline & 60 & $\mathrm{M}$ & 53 & $7 \mathrm{~d}$ & 96 & 67 & - \\
\hline & 75 & $\mathrm{~F}$ & 56 & $14 \mathrm{~d}$ & 92 & 66 & - \\
\hline & 73 & $\mathrm{M}$ & 59 & $4 \mathrm{yr}$ & 85 & 64 & - \\
\hline & 65 & M & 45 & $7 \mathrm{~d}$ & 72 & 73 & + \\
\hline
\end{tabular}

Definition of abbreviations: $\mathrm{FEV}_{1}$ (\% pred), forced expiratory volume in $1 \mathrm{~s} \%$ predicted; FVC, forced vital capacity; F, female; HRCT, high-resolution computed tomography; M, male.

(\% predicted). No differences were observed in age among the three groups (never-smoker, $65 \pm 5 \mathrm{yr}$; smoker without either airflow limitation or emphysema, $61 \pm 5 \mathrm{yr}$; smoker with airflow limitation and/or emphysema, $67 \pm 3 \mathrm{yr}$, NS). Both groups of smokers were similar in pack-years of smoking (smokers without either airflow limitation or emphysema, $52 \pm 15$ pack-years; smokers with airflow limitation and/or emphysema, $55 \pm 7$ pack years, NS) with various durations of smoking; seven of these subjects had stopped smoking within a month of this study. The group of smokers with airflow limitation and/or emphysema consisted of 7 subjects with $\mathrm{FEV}_{1} / \mathrm{FVC}$ under $70 \%$ and 3 subjects with emphysema without airflow limitation. In this group, the 7 patients who were identified as having emphysema had low attenuation areas comprising less than $25 \%$ of the total area on CT scans.

\section{LCM of Bronchiolar Epithelial Cells}

The bronchiolar epithelial cell layer is located and the laser is then pulsed over cells immediately adjacent to the lumen of the airway such that a portion of the beam is over the lumen to ensure that subepithelial cells are not directly in the path of the laser beam. Bronchioles from never-smokers showed thin walls with no evidence of muscle hypertrophy or fibrous tissue, and no apparent inflammatory cell number (Figure 1). In contrast, various abnormalities were observed in bronchioles from smokers, such as inflammatory cell infiltration, fibrosis, pigment deposition, and squamous metaplasia, regardless of airflow limitation and/or emphysema. Figure 2 shows the lung sections from a smoker with airflow limitation and emphysema who ceased smoking 16 yr ago.

\section{Immuno-LCM of Macrophages}

General dye-based histologic staining methods do not readily differentiate macrophages in lung tissues, and thus the immunohistochemical protocol used for LCM in this study was developed for definitive localization of macrophages. Lung sections were immunostained for anti-CD68 antibody. Instillation of TissueTek into the lung airways prevented alveolar collapse. Not only macrophages located in alveolar spaces, but also macrophages adjacent to or within the alveolar walls could be easily distinguished from alveolar epithelial cells. Immuno-LCM for macrophages is depicted in Figure 3. Figures $3 a-3 d$ show lung tissue from a never-smoker. Figures $3 \mathrm{e}-3 \mathrm{~h}$ show lung tissue from a smoker with emphysema who smoked cigarettes until $9 \mathrm{~d}$ before surgery. There are more aggregated macrophages present in the alveolar spaces of the smoker's lung than in the never-smoker's lung.

\section{IL-8, MIP-1 $\alpha$, and MCP-1 Expression in LCM-Retrieved Bronchiolar Epithelial Cells and Macrophages and in Whole Sections of Lung Tissue}

In LCM-retrieved bronchiolar epithelial cells, IL-8 mRNA/ GAPDH mRNA was significantly elevated in smokers with airflow limitation and/or emphysema when compared with smokers without airflow limitation or emphysema and never-smokers (median, 10.4; range, 4.4-68.4 versus median, 4.3; range: 1.2-14.8; and median, 5.6; range, 1.8-9.1; $P<0.05$ ) (Figure 4). MIP-1 $\alpha$ mRNA/ GAPDH mRNA was significantly elevated in smokers with airflow limitation and/or emphysema when compared with smokers without airflow limitation or emphysema (median, 1.3; range, 0.2-7.6 versus median, 0.6; range, 0.1-1.1; $P<0.05)$. MCP-1 mRNA/ 

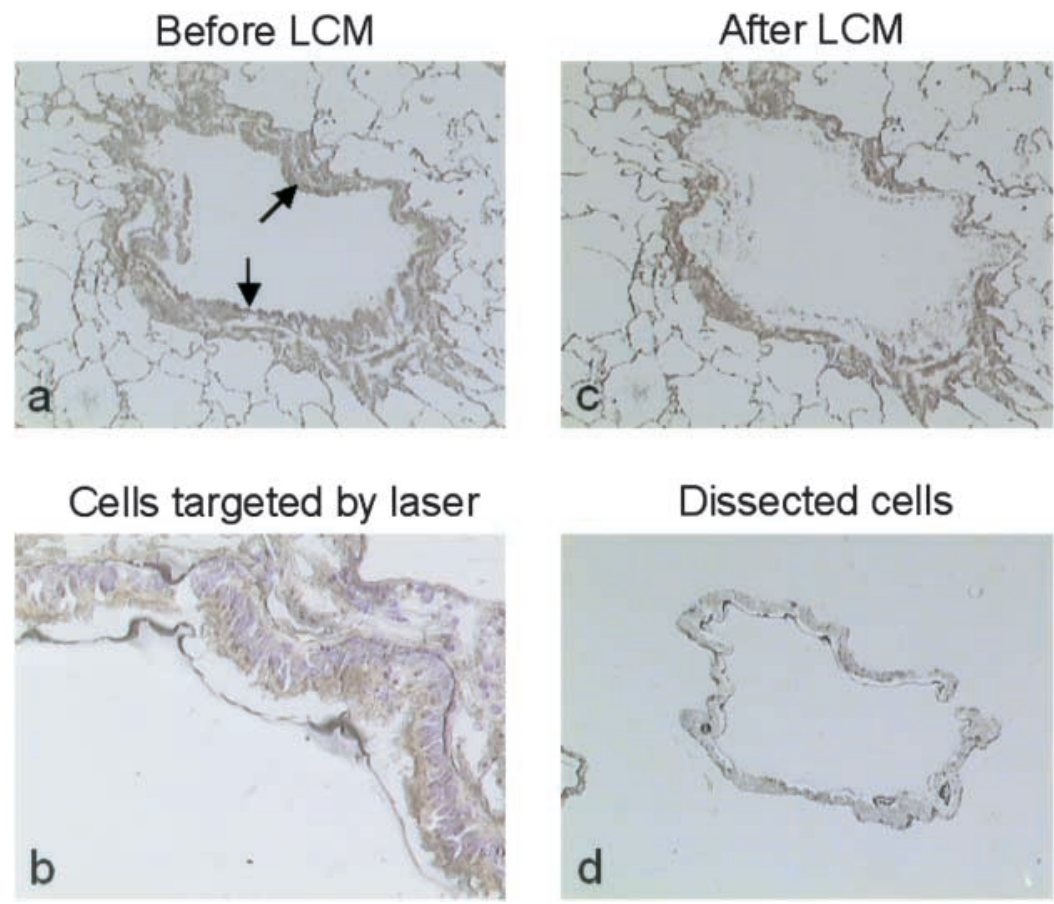

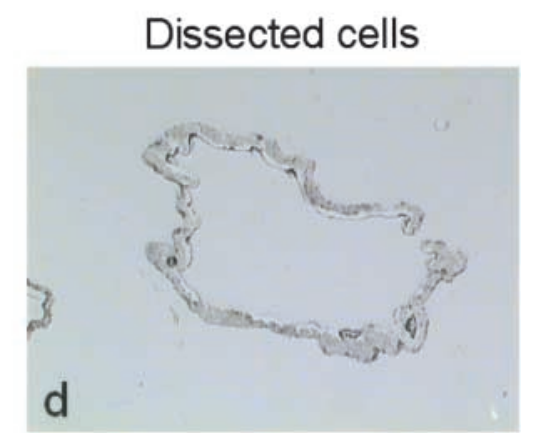

Figure 1. LCM of bronchiolar epithelial cells from a neversmoker. (a) Normal membranous bronchiole with thin wall (Nissl stain, original magnification $\times 40$ ). Bronchiolar epithelial cells are indicated with arrows. (b) Targeted bronchiolar epithelial cells, at which a $15-\mu \mathrm{m}$ diameter laser was pulsed during the LCM procedure $(\times 200)$. (c) Postdissection photo after removal of bronchiolar epithelial cells $(\times 40)$. Tissue surrounding the extracted cells remains intact after the procedure. $(d)$ LCM-captured bronchiolar epithelial cells on the capture disk $(\times 40)$.
GAPDH mRNA was also significantly elevated in smokers with airflow limitation and/or emphysema when compared with smokers without airflow limitation or emphysema and never-smokers (median, 7.8; range, 1.8-62.2 versus median, 2.6; range, 0.3-10.9; and median, 4.5; range, 0.9-16.6; $P<0.05$ ) (Figure 4). Among smokers with airflow limitation and/or emphysema, there were no correlations between these expression levels and $\mathrm{FEV}_{1} / \mathrm{FVC}$, diffusing capacity for carbon monoxide/alveolar volume or the severity of emphysematous changes on CT scans. Smoking status of these patients (former versus current smoker) had no effect on the levels of IL-8, MIP-1 $\alpha$, or MCP-1 expression. In Figures $4 \mathrm{a}$ and $4 \mathrm{c}$, the subject with the highest values of IL-8 and MCP-1 in bronchiolar epithelium is shown and is the same person, a 76 yr-old male with 56 pack-years of smoking in Table 1, while the level of MIP- $1 \alpha$ in this subject was third highest among the group of smokers with airflow limitation/emphysema (Figure 4b). The statistical significance of IL- 8 and MCP-1, but not of MIP-1 $\alpha$, remains even without inclusion of this one individual. Analysis of all subjects reveals a significant positive correlation between the levels of IL- 8 and MCP-1 mRNA in LCM-retrieved bronchiolar epithelial cells $(r=0.86, P<0.001)$.

In contrast, expression of IL- 8 , MIP- $1 \alpha$, and MCP-1 in LCMretrieved macrophages did not differ significantly among the three groups (Figure 5) and there was no significant intra-individual correlation between the expression levels of IL-8, MIP- $1 \alpha$, or MCP-1 in bronchiolar epithelial cells and those in macrophages.

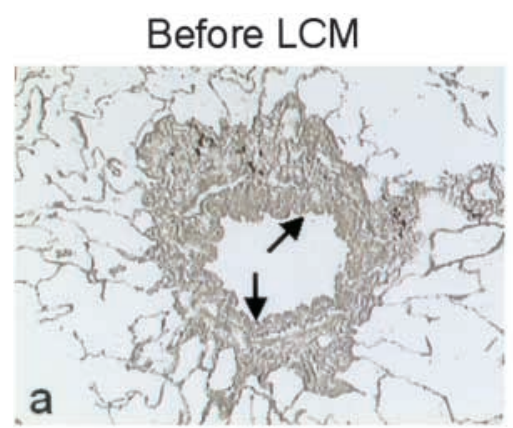

Cells targeted by laser

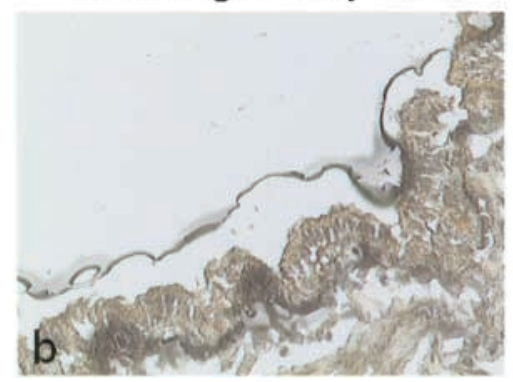

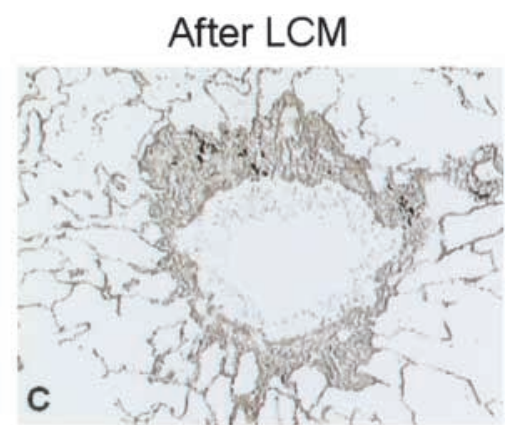

Dissected cells

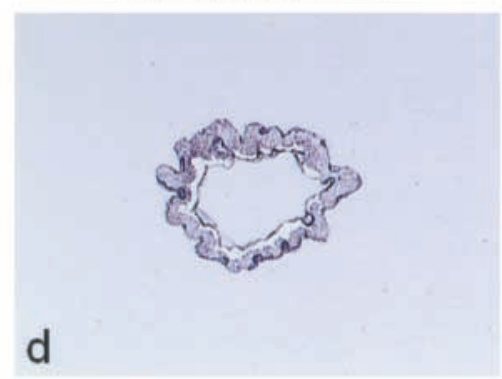

Figure 2. LCM of bronchiolar epithelial cells from a smoker with airflow limitation and emphysema. (a) Fibrosis of membranous bronchiole (Nissl stain, original magnification $\times 40$ ). Bronchiole wall is thickened with dense fibrosis. Destruction of alveolar walls and enlargement of alveolar spaces can also be seen. Bronchiolar epithelial cells are indicated with arrows. (b) Targeted bronchiolar epithelial cells, at which a $15-\mu \mathrm{m}$ diameter laser was pulsed during the LCM procedure $(\times 200)$. (c) Post-dissection photo after removal of bronchiolar epithelial cells $(\times 40)$. Peribronchiolar fibrotic tissues adjacent to extracted cells remain intact after the procedure. $(d)$ LCM-captured bronchiolar epithelial cells on the capture disk $(\times 40)$. 
(Never-smoker)

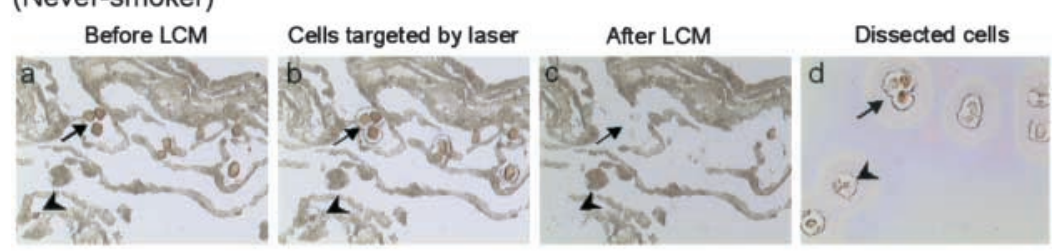

(Smoker with emphysema)

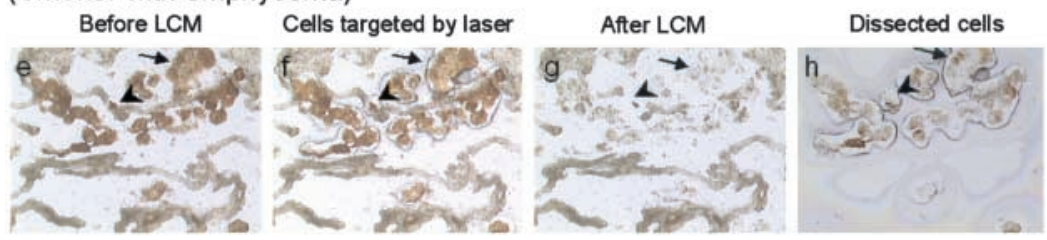

Figure 3. LCM of macrophages. $(a-d)$ Lung sections from a never-smoker and $(e-h)$ lung sections from a smoker with emphysema, but no airflow limitation. To identify macrophages in the lungs, sections were stained with mouse monoclonal anti-human CD68 antibodies. There are more clustered macrophages seen in the smoker's lung than in the never-smoker's lung. Arrows and arrowheads indicate alveolar macrophages and interstitial macrophages, respectively. ( $a-e)$ The lungs before LCM. Macrophages are identifiable in the given position next to the septum as well as in alveolar spaces. ( $b$ and $f$ ) The macrophages targeted by the 7.5- $\mu \mathrm{m}$ diameter laser pulses during the LCM procedure. ( $c$ and $g$ ) Post-dissection photos after removal of macrophages. Alveolar walls surrounding the harvested macrophages remain intact after the procedure. Arrows and arrowheads indicate the prior positions of alveolar macrophages and interstitial macrophages, respectively. ( $d$ and $h$ ) LCM-captured macrophages on the capture disk (original magnification $\times 200$ ).
In whole sections of lung tissue, expression of IL-8 and MCP-1 did not significantly differ among the three groups, although significant upregulation of MIP-1 $\alpha$ in smokers with airflow limitation and/or emphysema was observed when compared with smokers without airflow limitation or emphysema and neversmokers (median, 1.4; range, 0.6-5.4 versus median, 0.7; range, 0.2-1.2 and median, 0.8; range, 0.3-1.4; $P<0.05$ ) (Figure 6). The subject mentioned above also showed the highest values both in IL-8 and in MCP-1 in whole lung (Figures 6a and 6c), whereas the level of MIP-1 $\alpha$ was sixth highest among the smokers with airflow limitation/emphysema (Figure 6b).

\section{cDNA Array Analysis}

To screen multiple chemokine and chemokine receptor genes for expression in bronchiolar epithelial cells, cDNA array analysis was used (Figure 7, Table 2). IL-8 was upregulated in smokers with airflow limitation and/or emphysema compared with the others, which was consistent with the results of RT-PCR for individuals, as described above (Table 2, Figure 4). On the arrays,
CC chemokine receptor 2 (CCR2) was another gene of note, showing significant upregulation in smokers with airflow limitation and/or emphysema. In addition, it was revealed that the genes coding for Duffy blood group, growth-related oncogene 1 and 3, and leukotriene B4 receptor were constitutively expressed in bronchiolar epithelial cells and showed no differences among the three groups. Expression of MCP-1 and MIP- $1 \alpha$ were, however, below the detection limit of the array for all groups. To examine whether the low signals for MIP- $1 \alpha$ and MCP-1 were due to the poor sensitivity of this method, the RNA aliquot applied to the array from each group was tested for IL-8, MIP- $\alpha$, and MCP-1 by quantitative RT-PCR. All three genes were detectable in the same pooled RNA samples by RT-PCR and more than 2-fold increases were observed for each gene in smokers with airflow limitation and/or emphysema when compared with smokers without airflow limitation or emphysema, which was consistent with the results of RT-PCR for individuals as described above (Table 2, Figure 4). Quantitative RT-PCR thus proved more sensitive than the cDNA array for these genes. (a)

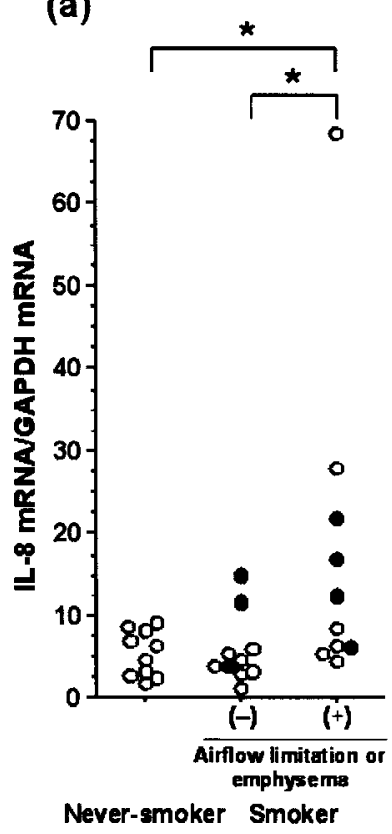

(b)

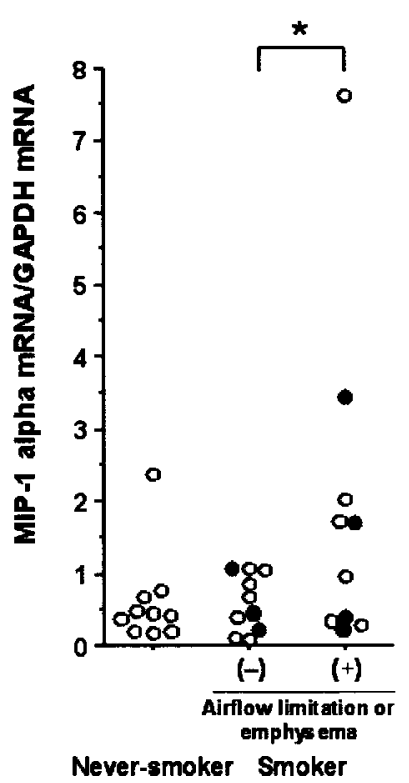

(c)

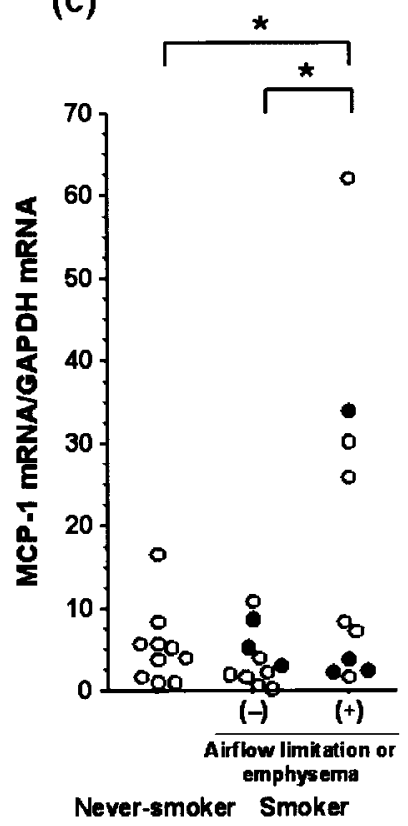

Figure 4. IL-8, MIP-1 $\alpha$, and MCP-1 expression in LCM-retrieved bronchiolar epithelial cells. (a) IL-8, $(b)$ MIP-1 $\alpha$, and (c) MCP-1. Expression of IL-8, MIP- $1 \alpha$, and MCP-1 was significantly elevated in smokers with airflow limitation and/or emphysema when compared with smokers without either airflow limitation or emphysema, respectively. Differences in IL-8 and MCP-1 expression between smokers with airflow limitation and/or emphysema and never-smokers were also seen. For smokers, length of cessation of smoking had no significant effect on these expression levels (open circles, smokers who stopped smoking more than a month before study; closed circles, smokers who stopped smoking less than a month before study). 
(a)

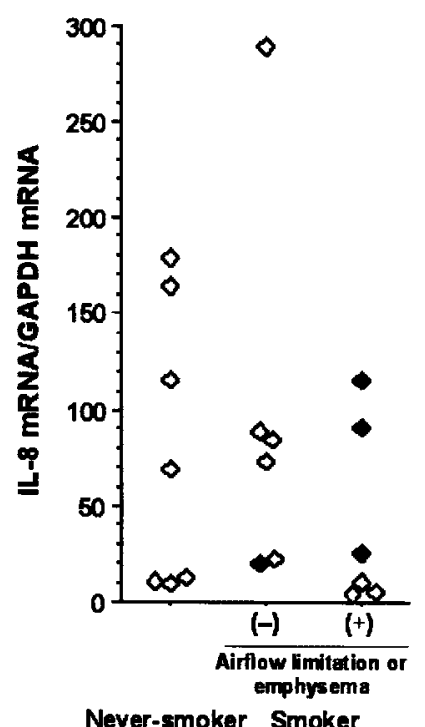

(b)

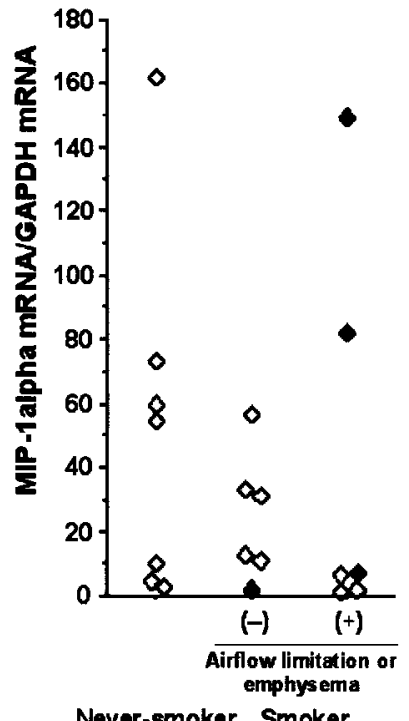

(c)

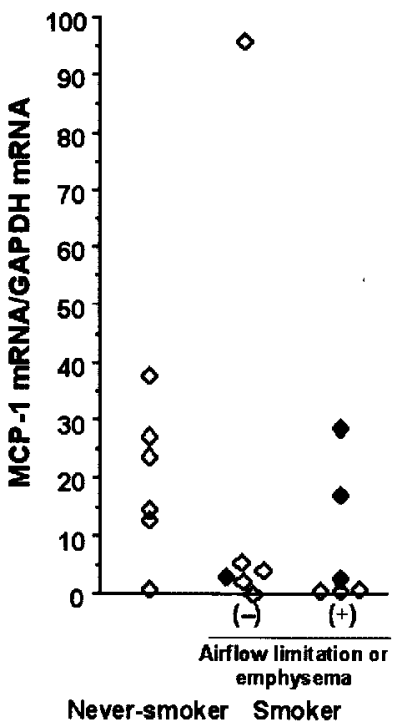

Figure 5. IL-8, MIP-1 $\alpha$, and MCP-1 expression in LCM-retrieved macrophages. (a) IL-8, $(b)$ MIP- $1 \alpha$, and $(c)$ MCP-1. Expression of IL-8, MIP-1 $\alpha$, and MCP-1 in LCM-retrieved macrophages did not differ significantly between never-smokers, smokers without either airflow limitation or emphysema, and smokers with airflow limitation and/or emphysema for 19 subjects tested. For smokers, the levels did not vary significantly with length of cessation of smoking (open diamonds, smokers who stopped smoking more than a month before study; closed diamonds, smokers who stopped smoking less than a month before study).

\section{Discussion}

The lungs are anatomically complex organs, and thus gene expression analysis using tissue homogenates inevitably results in average expression levels of all cells present. LCM allows a single type of cell from specific tissue sections to be retrieved, and thus provides an opportunity to perform quantitative RT-PCR from specific cell types (19). An increasing number of studies are now using laser-assisted microdissection techniques to analyze cellspecific gene expression in complex tissues (20). To date, however, the published application of LCM to retrieve lung structural cells has been mostly for animal models $(11,21)$. For human tissues, RNA extraction requires more stringent safeguards for tissue preservation as well as RNase-free conditions due to its higher sensitivity to degradation by ubiquitously present RNase. This is the first study to quantify inflammatory chemokine mRNA levels in two different cell types in human lung using LCM combined with RT-PCR and cDNA array to establish possible links with the pathogenesis of COPD.

Bronchiolar epithelial cells from patients with airflow limitation and/or emphysema demonstrated significantly elevated IL-8, MIP-1 $\alpha$, and MCP-1 expression when compared with smokers without either airflow limitation or emphysema, while no differences were observed between never-smokers and smokers without either airflow limitation or emphysema. In contrast, macrophages in the lungs did not differ with regard to mRNA levels for those genes among the three groups, despite a wide range of individual variation. Thus, irrespective of smoking history, having even mild airflow limitation and/or presence of mild parenchymal destructive changes are associated with elevations in inflammatory chemokine mRNA levels in bronchiolar epithelial cells, but not in macrophages. Our observations also suggest that a history of chronic smoking alone does not necessarily (a)

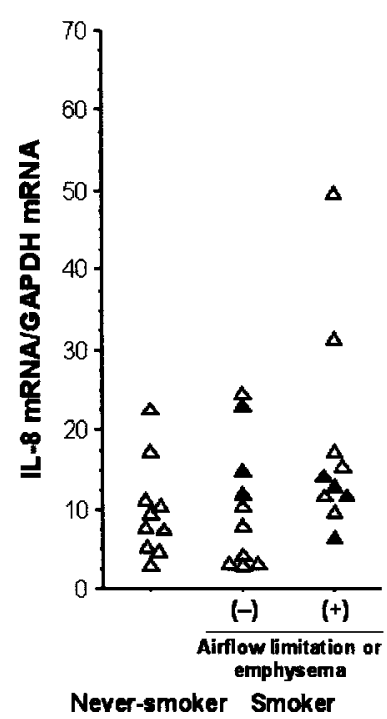

(b)

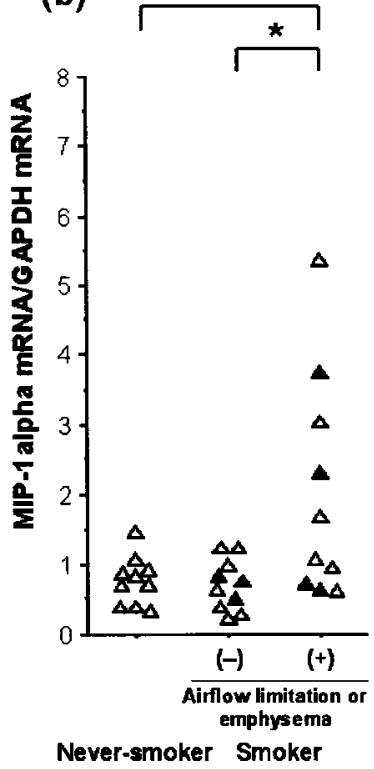

(c)

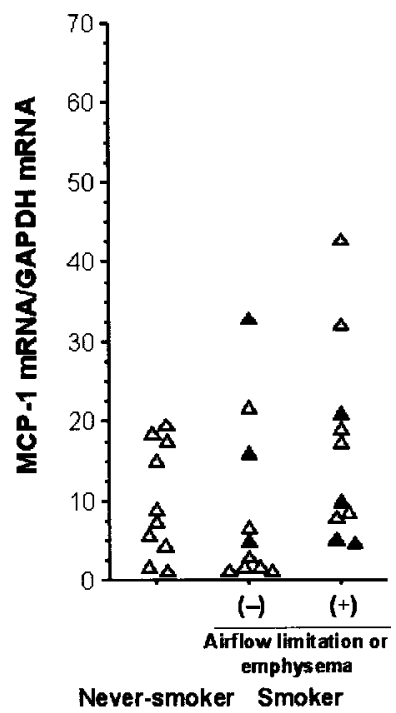

Figure 6. IL-8, MIP-1 $\alpha$, and MCP-1 expression in whole sections of lung tissue. (a) IL-8, (b) MIP-1 $\alpha$, and (c) MCP-1. Significant upregulation of MIP- $1 \alpha$ in smokers with airflow limitation and/or emphysema was observed when compared with the other two groups. On the other hand, IL- 8 and MCP-1 expression levels did not differ significantly between the three groups. For smokers, levels were not significantly affected by length of cessation of smoking (open triangles, smokers who stopped smoking more than a month before study; closed triangles, smokers who stopped smoking less than a month before study). 
(a) Never-smoker

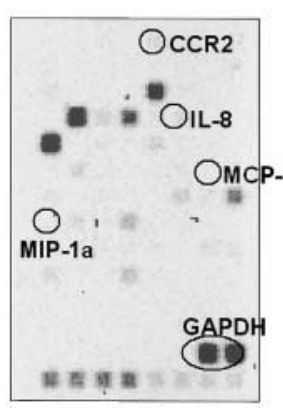

(b) Smoker without airflow

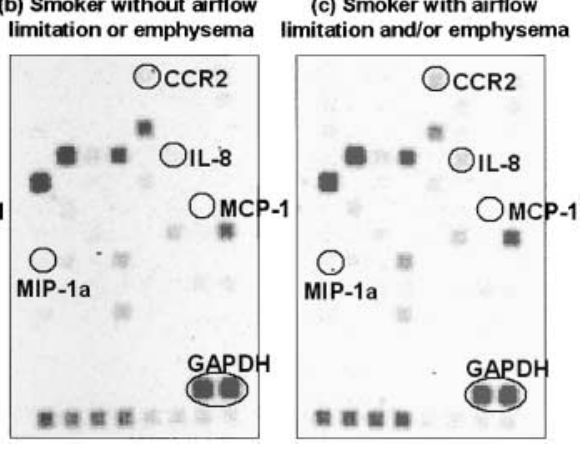

Figure 7. cDNA array analysis of chemokines and chemokine receptors in LCM-retrieved bronchiolar epithelial cells. Genes expressed are identified as a specific hybridization signal. (a) Never-smoker, $(b)$ smoker without either airflow limitation or emphysema, and $(c)$ smoker with airflow limitation and/or emphysema. Overexpression of IL-8 and CCR2 are noted in smokers with airflow limitation and/or emphysema.

alter the phenotype of either bronchiolar epithelial cells or macrophages to upregulate these inflammatory chemokines. The results further show that elevated expression of these chemokines may persist in bronchiolar epithelial cells, leading to recruitment of inflammatory cells, even after smoking cessation among patients developing COPD $(22,23)$.

For each chemokine gene, the range of expression levels was wide and mostly overlapped among the subject groups even though there were statistical differences among them. In addition, there was no significant correlation with disease severity among subjects with airflow limitation and/or emphysema. A likely explanation is that, due to the heterogeneity of the disease at early stages, the tissue specimens obtained did not necessarily reflect the phenomena at the site of airway obstruction and/ or parenchymal destruction. Although our interests have been focused on the pathogenesis of early-stage COPD, future investigation of patients with severe COPD is crucial for comparison. Even in the early stages of the disease, it should be taken into consideration that combining smokers having only airflow obstruction with smokers having only emphysema in one group may be mixing different types of disease pathogenesis.

Using the BAL technique, we examined what could differentiate current smokers having mild emphysema from individuals who had a similar smoking history, but who did not have emphysema. We found that the concentration of neutrophil-derived granular proteins, such as neutrophil elastase- $\alpha 1$ protease inhibitor complex (12), human neutrophil lipocalin, neutrophil collagenase (24), and IL-8 (15) are significantly elevated in BAL fluid from smokers with mild emphysema when compared with those without emphysema. These data provide evidence for neutrophil involvement in the early stages of pulmonary emphysema. IL-8 production was, however, rather suppressed in alveolar macrophages from smokers, thus suggesting that macrophages are unlikely to be the main cellular source of elevated IL-8 in BAL fluid from those subjects with emphysema (15). These results are consistent with the findings of De Boer and colleagues, who found that IL- 8 and MCP-1 mRNA levels were significantly higher in bronchiolar epithelial cells from subjects with COPD compared with those without COPD (7).

An advantage of LCM is the potential application of RNA derived from specific cell types to global gene expression analysis in vivo. Using a focused array for chemokine and chemokine receptors with gene-specific primers for cDNA synthesis, we were able to confirm the upregulation of IL-8 mRNA in bronchiolar epithelial cells from smokers with airflow limitation and/or emphysema when compared with those from the other two groups (Figure 7, Table 2). In addition, the array confirmed that another gene, CCR2, was markedly upregulated in smokers with airflow limitation and/or emphysema. Taken together with MCP-1 mRNA elevation by RT-PCR in bronchiolar epithelial cells in smokers with airflow limitation and/or emphysema, these data further support the theory that MCP-1 may have an autocrine effect on these cells and plays a major role in the MCP-1/ CCR2 system in airway remodeling and inflammation (8). Our results with cDNA arrays, however, illustrate the potential danger of depending solely on array analysis to identify changes in gene expression. The signal levels for MIP- $1 \alpha$ and MCP-1 were not sufficiently high to evaluate any differences between the groups on the array, although the same RNA samples pooled in each group had detectable levels in quantitative RT-PCR and supported the findings of individual analyses (Figure 4 and Table 2 ). These results indicate that RT-PCR is more sensitive and is able to detect expression at levels undetectable using the array approach, as was previously reported (25).

In contrast to the findings in the bronchiolar epithelium, none of the macrophage chemokine mRNAs tested were related to cigarette smoking, airflow limitation, or emphysema. It should be noted that IL- 8 and MIP- $1 \alpha$ mRNAs in macrophages are often present in much higher amounts than in epithelial cells, and that many macrophages in never-smokers have even higher levels than macrophages in smokers, as reported previously for IL-8 (15). Interestingly, the chemokine gene expression pattern of macrophages is not reflected in whole lung samples, suggesting that the population of macrophages is relatively small among the total number of lung cells. However, considering the increase in the number of macrophages induced by smoking, the relative role of macrophages as a potential source of inflammatory chemokines cannot be ignored.

The contribution of mRNAs from contaminating inflammatory cells in bronchiolar regions seems unlikely because none of the genes tested were altered in smokers without either airflow limitation or emphysema, who routinely have inflammatory cells in bronchiolar epithelium when compared with never-smokers

TABLE 2. Signal intensity of cDNA array and the expression of mRNA quantified by real-time RT-PCR in pooled laser-capture microdissection-retrieved bronchiolar epithelial cells in each group

\begin{tabular}{|c|c|c|c|c|c|c|}
\hline & \multicolumn{3}{|c|}{ cDNA Array* } & \multicolumn{3}{|c|}{$\mathrm{RT}^{-\mathrm{PCR}^{\dagger}}$} \\
\hline & IL-8 & MIP-1 $\alpha$ & MCP-1 & IL-8 & MIP-1 $\alpha$ & MCP-1 \\
\hline Never-smoker, $n=10$ & 0.086 & ND & ND & 3.08 & 0.27 & 2.79 \\
\hline Smoker without either airflow limitation or emphysema, $n=10$ & 0.065 & ND & ND & 2.27 & 0.13 & 0.83 \\
\hline Smoker with airflow limitation and/or emphysema, $n=10$ & 0.157 & ND & ND & 8.18 & 0.51 & 5.23 \\
\hline
\end{tabular}

Definition of abbreviations: IL, interleukin; MCP, monocyte chemoattractant protein; MIP, macrophage inflammatory protein; ND, not detected; RT-PCR, reverse transcriptase-polymerase chain reaction.

* The relative amount of a given gene transcript was estimated by comparing its signal intensity with the signal derived from GAPDH.

The relative amount of target mRNA in each sample was normalized against GAPDH mRNA. 
(26). It should be noted, however, that morphometric analyses have revealed a correlation between the increase in inflammatory cells in bronchiolar regions and the degree of airflow obstruction not only when COPD is severe (27), but also when it is mild (28). It is also noteworthy that after a long history of smoking exposure, bronchiolar epithelium potentially initiates antioxidant defenses (29) and undergoes morphologic alterations, such as increased numbers of Goblet cells, decreased numbers of Clara cells $(30,31)$, and squamous metaplasia, in association with wall inflammation and fibrosis $(32,33)$. Therefore, changes in gene expression in LCM-retrieved bronchiolar epithelial cells may reflect phenotypic changes in the resident cells or changes in the cell types located in these anatomic regions. Further research investigating the functional consequences of selective upregulation of these chemokines and the molecular mechanisms leading to phenotypic changes of bronchiolar epithelial cells, even after smoking cessation, during the development of COPD is required.

Quantitative analysis of gene expression in each cell type in vivo has been difficult because of the heterogeneity of cellular components and the diverse pathologic populations in the lung. LCM has allowed us to quantify and confirm upregulation of IL-8, MIP-1 $\alpha$, and MCP-1 mRNAs in bronchiolar epithelial cells, even in the early stages of COPD, thus emphasizing the pivotal role of bronchiolar epithelial-derived chemokines in driving the inflammation observed at this stage of the condition. The present study should encourage the use of LCM for further study of human lung diseases.

Conflict of Interest Statement: S.F. has no declared conflicts of interest; T.B. has no declared conflicts of interest; Y.N. has no declared conflicts of interest; T.M. has no declared conflicts of interest; H.K. has no declared conflicts of interest; and M.N. has no declared conflicts of interest.

Acknowledgments: The authors thank Dr. Robert M. Senior of the Washington University School of Medicine for his helpful comments and support during the course of this work and Ms. Yoko Suzuki for her invaluable technical assistance in performing LCM. This research was supported by the Respiratory Failure Research Group of the Ministry of Health, Labor, and Welfare of Japan to M.N. and scientific research grants from the Ministry of Education, Science, Culture and Sports of Japan (13470125 to M.N. and 14570532 to T.B.)

\section{References}

1. Vial, W. C. 1986. Cigarette smoking and lung disease. Am. J. Med. Sci. 291:130142

2. Hogg, J. C., P. T. Macklem, and W. M. Thurlbeck. 1968. Site and nature of airway obstruction in chronic obstructive lung disease. N. Engl. J. Med. 278 1355-1360.

3. Hogg, J. C., and R. M. Senior. 2002. Chronic obstructive pulmonary diseasepart 2: pathology and biochemistry of emphysema. Thorax 57:830-834.

4. Di Stefano, A., A. Capelli, M. Lusuardi, P. Balbo, C. Vecchio, P. Maestrelli, C. E. Mapp, L. M. Fabbri, C. F. Donner, and M. Saetta. 1998. Severity of airflow limitation is associated with severity of airway inflammation in smokers. Am. J. Respir. Crit. Care Med. 158:1277-1285.

5. Mio, T., D. J. Romberger, A. B. Thompson, R. A. Robbins, A. Heires, and S. I. Rennard. 1997. Cigarette smoke induces interleukin-8 release from human bronchial epithelial cells. Am. J. Respir. Crit. Care Med. 155:17701776 .

6. Takizawa, H., M. Tanaka, K. Takami, T. Ohtoshi, K. Ito, M. Satoh, Y. Okada F. Yamasawa, and A. Umeda. 2000. Increased expression of inflammatory mediators in small-airway epithelium from tobacco smokers. Am. J. Physiol. Lung Cell. Mol. Physiol. 278:L906-L913.

7. De Boer, W. I., J. K. Sont, A. van Schadewijk, J. Stolk, J. H. van Krieken, and P. S. Hiemstra. 2000. Monocyte chemoattractant protein 1, interleukin 8, and chronic airways inflammation in COPD. J. Pathol. 190:619-626.

8. De Boer, W. I. 2002. Cytokines and therapy in COPD: a promising combination? Chest 121:209S-218S.

9. Eltoum, I. A., G. P. Siegal, and A. R. Frost. 2002. Microdissection of histologic sections: past, present, and future. Adv. Anat. Pathol. 9:316-322.
10. Emmert-Buck, M. R., R. F. Bonner, P. D. Smith, R. F. Chuaqui, Z. Zhuang, S. R. Goldstein, R. A. Weiss, and L. A. Liotta. 1996. Laser capture microdissection. Science 274:998-1001.

11. Betsuyaku, T., G. L. Griffin, M. A. Watson, and R. M. Senior. 2001. Laser capture microdissection and real-time reverse transcriptase/polymerase chain reaction of bronchiolar epithelium after bleomycin. Am. J. Respir. Cell Mol. Biol. 25:278-284.

12. Yoshioka, A., T. Betsuyaku, M. Nishimura, K. Miyamoto, T. Kondo, and Y. Kawakami. 1995. Excessive neutrophil elastase in bronchoalveolar lavage fluid in subclinical emphysema. Am. J. Respir. Crit. Care Med. 152:2127-2132.

13. Fend, F., M. R. Emmert-Buck, R. Chuaqui, K. Cole, J. Lee, L. A. Liotta, and M. Raffeld. 1999. Immuno-LCM: laser capture microdissection of immunostained frozen sections for mRNA analysis. Am. J. Pathol. 154:61-66.

14. Trogan, E., R. P. Choudhury, H. M. Dansky, J. X. Rong, J. L. Breslow, and E. A. Fisher. 2002. Laser capture microdissection analysis of gene expression in macrophages from atherosclerotic lesions of apolipoprotein E-deficient mice. Proc. Natl. Acad. Sci. USA 99:2234-2239.

15. Tanino, M., T. Betsuyaku, K. Takeyabu, Y. Tanino, E. Yamaguchi, K. Miyamoto, and M. Nishimura. 2002. Increased levels of interleukin-8 in BAL fluid from smokers susceptible to pulmonary emphysema. Thorax 57:405411.

16. Gibson, U. E., C. A. Heid, and P. M. Williams. 1996. A novel method for realtime quantitative RT-PCR. Genome Res. 6:995-1001.

17. Betsuyaku, T., M. Tanino, K. Nagai, Y. Nasuhara, M. Nishimura, and R. M. Senior. 2003. Extracellular matrix metalloproteinase inducer is increased in smokers' bronchoalveolar lavage fluid. Am. J. Respir. Crit. Care Med. 168: 222-227.

18. Sharif, S., G. A. Arreaza, P. Zucker, Q. S. Mi, J. Sondhi, O. V. Naidenko, M. Kronenberg, Y. Koezuka, T. L. Delovitch, J. M. Gombert, M. Leite-DeMoraes, C. Gouarin, R. Zhu, A. Hameg, T. Nakayama, M. Taniguchi, F. Lepault, A. Lehuen, J. F. Bach, and A. Herbelin. 2001. Activation of natural killer T cells by alpha-galactosylceramide treatment prevents the onset and recurrence of autoimmune Type 1 diabetes. Nat. Med. 7:1057-1062.

19. Betsuyaku, T., and R. M. Senior. 2004. Laser capture microdissection and mRNA characterization of mouse airway epithelium. Micron 35:229-234.

20. Burgess, J. K., and B. E. McParland. 2002. Analysis of gene expression. In Laser Capture Microscopy. M. P. Conn, editor. Academic Press, San Diego. p. $259-270$.

21. Wright, J. L., H. Tai, J. Dai, and A. Churg. 2002. Cigarette smoke induces rapid changes in gene expression in pulmonary arteries. Lab. Invest. 82:1391-1398.

22. Rutgers, S. R., D. S. Postma, N. H. ten Hacken, H. F. Kauffman, T. W. van Der Mark, G. H. Koeter, and W. Timens. 2000. Ongoing airway inflammation in patients with COPD who do not currently smoke. Thorax 55:12-18.

23. Retamales, I., W. M. Elliott, B. Meshi, H. O. Coxson, P. D. Pare, F. C. Sciurba, R. M. Rogers, S. Hayashi, and J. C. Hogg. 2001. Amplification of inflammation in emphysema and its association with latent adenoviral infection. Am. J. Respir. Crit. Care Med. 164:469-473.

24. Betsuyaku, T., M. Nishimura, K. Takeyabu, M. Tanino, P. Venge, S. Xu, and Y. Kawakami. 1999. Neutrophil granule proteins in bronchoalveolar lavage fluid from subjects with subclinical emphysema. Am. J. Respir. Crit. Care Med 159:1985-1991.

25. Luo, Y., J. Cai, Y. Liu, H. Xue, F. J. Chrest, R. P. Wersto, and M. Rao. 2002. Microarray analysis of selected genes in neural stem and progenitor cells J. Neurochem. 83:1481-1497.

26. Niewoehner, D. E., J. Kleinerman, and D. B. Rice. 1974. Pathologic changes in the peripheral airways of young cigarette smokers. N. Engl. J. Med. 291: $755-758$.

27. Turato, G., R. Zuin, M. Miniati, S. Baraldo, F. Rea, B. Beghe, S. Monti, B. Formichi, P. Boschetto, S. Harari, A. Papi, P. Maestrelli, L. M. Fabbri, and M. Saetta. 2002. Airway inflammation in severe chronic obstructive pulmonary disease: relationship with lung function and radiologic emphysema. Am. J. Respir. Crit. Care Med. 166:105-110.

28. Saetta, M., R. Finkelstein, and M. Cosio. 1994. Morphological and cellular basis for airflow limitation in smokers. Eur. Respir. J. 7:1505-1515.

29. Hackett, N. R., A. Heguy, B. G. Harvey, T. P. O'Connor, K. Luettich, D. B. Flieder, R. Kaplan, and R. G. Crystal. 2003. Variability of antioxidantrelated gene expression in the airway epithelium of cigarette smokers. Am. J. Respir. Cell Mol. Biol. 29:331-343.

30. Ebert, R. V., and M. J. Terracio. 1975. The bronchiolar epithelium in cigarette smokers: observations with the scanning electron microscope. Am. Rev. Respir. Dis. 111:4-11.

31. Lumsden, A. B., A. McLean, and D. Lamb. 1984. Goblet and Clara cells of human distal airways: evidence for smoking-induced changes in their numbers. Thorax 39:844-849.

32. Saetta, M., G. Turato, F. Luppi, and L. M. Fabbri. 2002. Inflammation in the pathogenesis of chronic obstructive pulmonary disease. In Chronic Obstructive Pulmonary Diseases. N. F. Voelkel and W. MacNee, editors. BC Dekker, Hamilton, Canada. p. 114-126.

33. Wright, J. L., M. Cosio, B. Wiggs, and J. C. Hogg. 1985. A morphologic grading scheme for membranous and respiratory bronchioles. Arch. Pathol. Lab. Med. 109:163-165. 